\title{
Observed and predicted measurements of photosynthesis in a phytoplankton culture exposed to natural irradiance
}

\author{
John Marra, Kristina Heinemann \& Gene Landriau, Jr. \\ Lamont-Doherty Geological Observatory of Columbia University, Palisades, New York 10964, USA
}

\begin{abstract}
Photosynthesis-irradiance (P-I) curves were produced (using artificial illumination) from samples taken at one or more times per day from a continuous culture illuminated with sunlight. The continuous culture housed an oxygen electrode used to measure photosynthises semi-continuously. Rates of photosynthesis predicted from P-I curves agreed with photosynthises observed in the culture only for days of low irradiance. For sunny days or for days of variable irradiance, P-I curves predicted neither the morning photosynthesis maximum nor the afternoon depression. Daily integrals of predicted and observed photosynthesis, however, were probably within the possible errors of measurement.
\end{abstract}

\section{INTRODUCTION}

Estimates of integral primary production of a lake or ocean area are usually based upon the equation

$$
P[\mathrm{z}, \mathrm{t}]=\iint_{2} \mathrm{p}[\mathrm{z}, \mathrm{t}] \mathrm{dtd} \mathrm{z}
$$

where $\mathrm{p}=$ instantaneous photosynthetic rate at a particular depth $(\mathrm{z})$ and time $(\mathrm{t}) ; P[\mathrm{z}, \mathrm{t}]=$ desired value, the water-column rate of primary production over a useful time period, usually $1 \mathrm{~d}$. Equation (1) greatly oversimplifies production dynamics, but illustrates the 2 primary ingredients to the estimate: the depth integral of photosynthesis and the integration over time.

The areal rate of production $(P[z])$ can be determined experimentally, and if temporal variations in environmental parameters which might influence the rate are neglected, in situ methods can give estimates of $P[\mathrm{z}, \mathrm{t}]$. But as discussed by Fee $(1969,1973)$ and others, these methods are impractical in most situations, and this purely empirical approach is unlikely to have much predictive capability without amassing a very large data set. Instead, the functional dependencies of $p[z, t]$ on environmental parameters (e.g. light, temperature, nutrients), or on biological parameters (e.g. cell size, pigments, nutrient pools), have been studied in order to formulate models that will allow predictions of daily water-column production. As pointed out by Platt et al. (1977), most of the variability in p appears to come about through variations in light, and there exist several semi-empirical models describing the functional dependence of photosynthesis on light. This functional dependence is known as the photosynthesis-irradiance (P-I) curve (e.g. Talling 1957, Steele 1962, Vollenweider 1965, Jassby \& Platt 1976). These models have the general form

$$
\mathrm{p}=\mathrm{f}(\mathrm{I}, \mathrm{a} 1, \mathrm{a} 2)
$$

where $\mathrm{I}=$ irradiance; $\mathrm{a} 1$ and $\mathrm{a} 2=$ constants determining the shape of the curve; $f=a$ saturating function. We have retained $p$ as the rate of photosynthesis determined in the P-I measurement, although because it is determined through an incubation technique, it is not strictly a measure of the instantaneous rate $\mathrm{p}[\mathrm{t}]$. Employing light as the primary independent variable also has the advantage that $I(z, t)$ is relatively easily measured and well-predicted.

The primary strategy, therefore, for modeling primary production over the last several years has been to use P-I curves derived from samples of phytoplankton to predict $P[\mathrm{z}, \mathrm{t}]$ (e.g. Vollenweider 1970, Fee 1973, Harris 1973, Platt \& Jassby 1976, Platt et al. 1977). Yentsch (1980) has called P-I curves 'fundamental' to modeling efforts and a 'cornerstone in studies of phytoplankton ecology'. Yet because measurements of $p$ are superseded by the modeling method, the actual rate of photosynthesis remains unknown. Therefore, it is difficult, if not impossible, to assess the accuracy of $P[\mathrm{z}, \mathrm{t}]$. 
We have performed P-I measurements on samples taken from continuous cultures of diatoms which were illuminated by sunlight and which held an oxygen electrode, allowing semi-continuous estimates of photosynthesis to be recorded (Marra \& Heinemann 1982). The oxygen electrode measures $\mathrm{p}[\mathrm{t}]$ in 2 to 10 min averages in the culture (but, of course, not $p[z]$ ), and $\mathrm{p}[\mathrm{t}] \mathrm{can}$ be integrated over the photoperiod to give estimates of $P[t]$. The curves fitted to the P-I data can be used to predict $\mathrm{p}[\mathrm{t}]$, using the recorded irradiance as the input variable. The P-I curves can also be integrated to check the direct estimates of $P[t]$ obtained using the oxygen electrode data. The concept of these experiments is that the culture represents an approximation to a natural population for which we have detailed information on instantaneous $(\mathrm{p}[\mathrm{t}])$ and integral photosynthesis $(P[t])$. We can thereby test, in a limited sense, the use of P-I curves for these same variables and gain some preliminary clues on how they might best be applied to natural populations.

Any comparison between P-I curves and direct rates of photosynthesis raises a number of questions; the topic is very broad. For example, there is the question of which analytical formulation to use for the P-I relationship (Jassby \& Platt 1976). Since the photosynthesis-irradiance relationship is normally non-linear, there are 2 or 3 parameters in the equations used to fit the data which assume importance over different regions of the irradiance gradient. These parameters, such as the commonly used $\alpha$ and $p_{\max }$ probably indicate different physiological processes, and consequently different time scales of variation. Agreement between predicted and observed $\mathrm{p}[\mathrm{t}]$ might be affected by mean I, maximum I, or the variance of $\mathrm{I}$. There is also the question of how the P-I data should be collected, that is, what the incubation period should be, the light source, etc. We have not attempted a complete evaluation of P-I curves. That is not possible given the experimental design, the reliance on laboratory cultures, and the limitations in our facilities. We have employed a commonly used P-I formulation, and have used standard methods where possible in collecting the data. Although our results are limited in several respects, our purpose is to suggest further experimentation in learning how P-I curves might be applied to the problem of primary production measurements in the natural environment.

\section{METHODS}

Details of methods and photosynthesis measurements with the oxygen electrode have been described in Marra (1978) and Marra \& Heinemann (1982). Briefly, photosynthetic oxygen was measured using a
YSI 5331 oxygen electrode inserted into a port in a water-jacketed culture vessel. The culture vessel was situated in a south-facing window greenhouse. The electrode signal was sent to a picoammeter (Kiethley, Model 480) and recorded on a strip-chart recorder. Air was supplied to the culture in discrete periods, the 'airoff' period allowing the photosynthesis measurement. This air-off period lasted from 2 to $10 \mathrm{~min}$, depending on the experiment, over which oxygen evolution was averaged. We have assumed this to be an estimate of $\mathrm{p}[\mathrm{t}]$. Incident irradiance was measured using a Lambda Instruments quantum sensor mounted directly in front of the culture vessel. Instantaneous values were recorded on the strip-chart recorder, and were also accumulated in an integrator corresponding to the period of photosynthesis measurement. The culture was continually replenished by nutrient media. That the culture was nutrient sufficient was established by a previous experiment. The harvest was transferred to a fraction collector for later cell counting, performed on a Coulter Counter.

The P-I curves were produced in 2 ways: (1) from dissolved oxygen evolution by samples placed in a cuvette and exposed to a range of light intensities (tungsten bulb) $;(2)$ by ${ }^{14} \mathrm{C}$-uptake in subsamples dispensed into bottles and placed in an artificial light incubator.

For the P-I curves derived from dissolved oxygen measurements, a few $\mathrm{ml}$ were withdrawn from the culture and subsamples were set aside for cell counts (hemocytometer) and chlorophyll a analysis (fluorometry). The final subsample was placed in a speciallydesigned cuvette for oxygen evolution measurement. The cuvette was temperature-controlled, and stirring was maintained using a teflon-coated magnetic bar suspended in the cuvette by means of a glass journalmounted bearing on the end of a glass rod. The oxygen electrode was a YSI 5331 whose signal was passed to a Gilson oxygraph. Light was supplied from a $300 \mathrm{~W}$ tungsten bulb and passed through a compound (water and $\mathrm{CuSO}_{4}$ solution) filter before reaching the cuvette surface. Light was attenuated by layers of neutral density screening. Light levels were measured through the sample using a Lambda Instruments quantum sensor, and ranged from 6 to $1000 \mu$ Einsteins $\mathrm{m}^{-2} \mathrm{~s}^{-1}$. The sample was exposed to 7 different irradiance levels for 10 min each during the course of the measurement, in random order and interspersed with periods of darkness.

For the P-I curves derived from ${ }^{14} \mathrm{C}$-uptake, samples were taken and subsampled as in the oxygen evolution measurements, except that the subsample was further subdivided into six $30 \mathrm{ml}$ reagent bottles which had been previously filled with (sterilized) $\mathrm{f} / 4$ media. The bottles were innoculated with a solution of $\mathrm{NaH}^{14} \mathrm{CO}_{3}$ 
with an activity of $5 \mu \mathrm{Ci} \mathrm{ml} \mathrm{m}^{-1}$. The bottles were placed in a fluorescent light incubator kept at $20^{\circ} \mathrm{C}$ at light levels of $100,55,18,9$, and $1 \%$ of ambient light. Actual irradiances varied from 10 to $1000 \mu$ Einsteins $\mathrm{m}^{-2} \mathrm{~s}^{-1}$. At this time, 1 sample was filtered for a 'time zero' value. The incubation itself lasted 1 to $2 \mathrm{~h}$. The samples were filtered onto glass fiber filters and the filters placed in liquid scintillation vials with a water-compatible fluor and counted in a Beckmann LS100 scintillation counter.

We chose the hyperbolic tangent equation first discussed by Jassby \& Platt (1976) as the P-I formulation used to evaluate the relationship between observed and predicted values of photosynthesis:

$$
\mathrm{p}=\mathrm{p}_{\max } \tanh \left(\alpha \mathrm{I} / \mathrm{p}_{\max }\right)-\mathrm{R}
$$

where $\mathrm{p}_{\max }=$ light-saturated rate of photosynthesis; $\alpha=$ initial slope of the P-I curve; and $\mathrm{R}=\mathrm{y}$-coordinate intercept. In relation to other formulations, this equation has been found to be successful in describing P-I data from a wide variety of environments (Jassby \& Platt 1976, Gallegos \& Platt 1981, Malone \& Neale 1981, P. J. Neale unpubl.).

The photosynthetic parameters $\alpha$ and $p_{\max }$ were estimated using the statistical method outlined in Malone \& Neale (1981). A polynomial was fitted to the experimental data to obtain values for $\alpha, p_{\max }$ and $R$, and these estimates were in turn used in Equation (3). Standard errors for $\mathrm{p}_{\max }, a$ and R were typically 10,20 , and $100 \%$ of the reported values, respectively. $\mathrm{R}$ was not significantly different from zero, and is not considered in this analysis. For the comparison with observed photosynthesis, p was determined using values of irradiance observed for the day in which the $P$ vs I measurements were made. For days where multiple $\mathrm{P}$ vs I measurements were made, the observed irradiance values were subdivided according to when the samples were drawn from the culture, each sampling time representing the mid-point between previous (or sunrise) and successive (or sunset) measurements.

\section{RESULTS}

Table 1 summarizes the data from the experiments comparing observed and predicted photosynthesis. The results portrayed in Fig. 2, 3 and 4 are selected from this data because they exemplify particular aspects of the comparison.

Fig. 1. shows an example of the diurnal behavior in P-I curves using the oxygen evolution technique. Morning P-I curves all have higher $p_{\max }$ and $\alpha$ values, and we usually observe a slight depression in these in late morning (e.g. the 0930 curve in Fig. 1) compared to the 0630 values. Afternoon P-I curves are uniformly low compared to those determined in the morning. The lower photosynthetic capacity evident in the afternoon curves, then, may affect their usefulness in a predictive

Table 1 Lauderia borealis (Lb) and Thalassiosira fluviatilis (Tf). List of the experiments performed to compare P-I curve-based predictions of total daily photosynthesis. P-I method is based on either the ${ }^{14} \mathrm{C}$ or $\mathrm{O}_{2}$ technique described in the Methods section. The hour during the day at which these experiments were performed is also listed. Daily irradiance (Total I) is given in Einsteins $\mathrm{m}^{-2}$ Daily integral photosynthesis either predicted from the P-I curves (PRE) or observed in the culture (OBS) is given in pmols $\mathrm{O}_{2}$ or C per cell

\begin{tabular}{|c|c|c|c|c|c|c|c|c|}
\hline Date & $\begin{array}{l}\text { Julian } \\
\text { date }\end{array}$ & $\begin{array}{c}\text { P-I } \\
\text { method }\end{array}$ & P-I times & Total I & PRE & OBS & OBS/PRE & Org. \\
\hline Mar 20/81 & 79 & ${ }^{14} \mathrm{C}$ & $08,10,13,16$ & 3.37 & 58.40 & 62.60 & 1.07 & $\mathrm{Lb}$ \\
\hline Apr 07/81 & 97 & ${ }^{14} \mathrm{C}$ & 12 & 8.07 & 6.92 & 7.18 & 1.04 & Tf \\
\hline Apr 08/81 & 98 & ${ }^{14} \mathrm{C}$ & $07,10,13,16$ & 6.40 & 14.51 & 20.24 & 1.40 & Tf \\
\hline Aрг 09/81 & 99 & ${ }^{14} \mathrm{C}$ & 12,16 & 2.62 & 5.99 & 8.32 & 1.39 & Tf \\
\hline Apr 10/81 & 100 & ${ }^{14} \mathrm{C}$ & $07,10,13,16$ & 7.78 & 15.82 & 11.09 & 0.70 & $\mathrm{Tf}$ \\
\hline Apr $13 / 81$ & 103 & ${ }^{14} \mathrm{C}$ & 12 & 7.45 & 10.26 & 11.43 & 1.11 & $\mathrm{Tf}$ \\
\hline Apr $15 / 81$ & 105 & ${ }^{14} \mathrm{C}$ & $08,10,12,16$ & 6.86 & 11.20 & 10.30 & 0.92 & $\mathrm{Tf}$ \\
\hline Apr $17 / 81$ & 107 & $\mathrm{O}_{2}$ & 12 & 0.95 & 4.96 & 4.52 & 0.91 & $\mathrm{Tf}$ \\
\hline Apr $20 / 81$ & 110 & $\mathrm{O}_{2}$ & 13,15 & 4.95 & 12.54 & 8.66 & 0.69 & $\mathrm{Tf}$ \\
\hline Apr $21 / 81$ & 111 & $\mathrm{O}_{2}$ & 13 & 6.52 & 8.99 & 13.20 & 1.47 & $\mathrm{Tf}$ \\
\hline Apr $23 / 81$ & 113 & $\mathrm{O}_{2}$ & 09 & 0.83 & 3.45 & 2.87 & 0.83 & $\mathrm{Tf}$ \\
\hline Арг $24 / 81$ & 114 & $\mathrm{O}_{2}$ & 12,15 & 2.98 & 7.32 & 5.03 & 0.69 & $\mathrm{Tf}$ \\
\hline Apr $27 / 81$ & 117 & $\mathrm{O}_{2}$ & 12 & 5.18 & 11.08 & 7.36 & 0.66 & Tf \\
\hline Apr $28 / 81$ & 118 & $\mathrm{O}_{2}$ & 12 & 2.02 & 5.32 & 6.40 & 0.75 & $\mathrm{Tf}$ \\
\hline Apr $29 / 81$ & 119 & $\mathrm{O}_{2}$ & 08,10 & 1.09 & 8.24 & 6.70 & 0.81 & $\mathrm{Tf}$ \\
\hline Apr $30 / 81$ & 120 & $\mathrm{O}_{2}$ & $06,10,12,16$ & 1.58 & 6.68 & 5.89 & 0.88 & Tf \\
\hline May 01/81 & 121 & $\mathrm{O}_{2}$ & 08 & 2.81 & 17.22 & 6.91 & 0.40 & $\mathrm{Tf}$ \\
\hline Oct $31 / 80$ & 286 & $\mathrm{O}_{2}$ & 12 & 12.10 & 27.40 & 26.20 & 0.96 & Tf \\
\hline
\end{tabular}




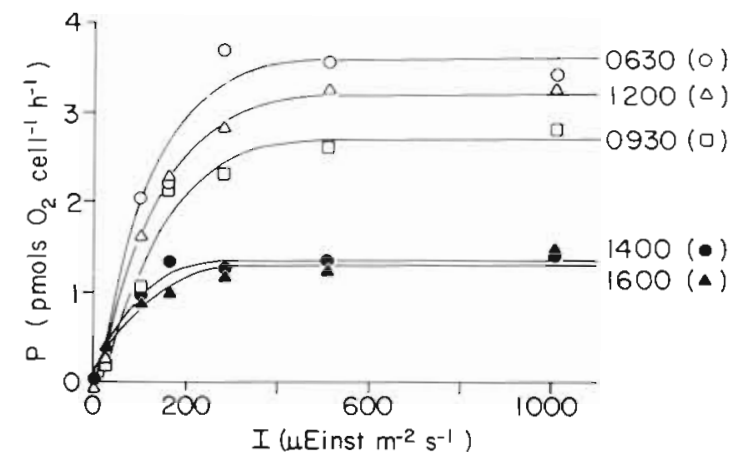

Fig. 1. P vs I data and fitted P-I curves (using Eq. 3) for 5 experiments taken over the course of 1 daytime period. $\mathrm{P}=$ photosynthesis; I = irradiance

sense; however, to the extent that daily photosynthesis will exhibit a morning maximum and an afternoon depression (Marra 1980), crude agreement is possible. The distribution of these curves agrees, in general, with other work on the temporal dependence of P-I parameters (Prezelin \& Matlick 1980, Harding et al. 1983).

Fig. 2, 3 and 4 show examples of the predicted $v s$ observed photosynthesis comparison for 3 types of days: cloudy, sunny and days in which irradiance was highly variable. How well the predicted photosynthesis agrees with the observed values is based on 3 factors: maximum irradiance, time at which the $\mathrm{P}$ vs I measurements were made, and irradiance variability.

Generally, if the maximum light achieved during the day is low, as on a cloudy day (or for phytoplankton confined to the deeper part of the euphotic zone), both observed photosynthesis and that predicted on the basis of P-I curves follow irradiance very closely (Fig. 2 ). The agreement in these cases is not significantly improved by altering the time at which the $\mathrm{P}$ vs I measurement is made.

At higher irradiances, however, the agreement between observed and predicted photosynthesis breaks down. The P-I curves do not predict the latemorning maximum in observed photosynthesis, and over-estimate actual photosynthesis during the afternoon depression (Fig. 3). Time of sampling for the P-I curve could be important for sunny days. For example, a $\mathrm{P}$ vs I measurement made during the afternoon depression (Fig. 3b) has a low $\mathrm{p}_{\max }$ even though its predicted values are about 3 times that observed. When extrapolated back to morning values, the P-I derived photosynthesis values underestimate the morning photosynthesis maximum. Although P-I measurements made on morning samples have higher $\mathrm{p}_{\max }$ values (Fig. 1 \& 3b), the asymmetry between predicted and observed photosynthesis is still very apparent. The series of P-I curves predict neither the morning maximum nor afternoon depression (Fig. 3a).
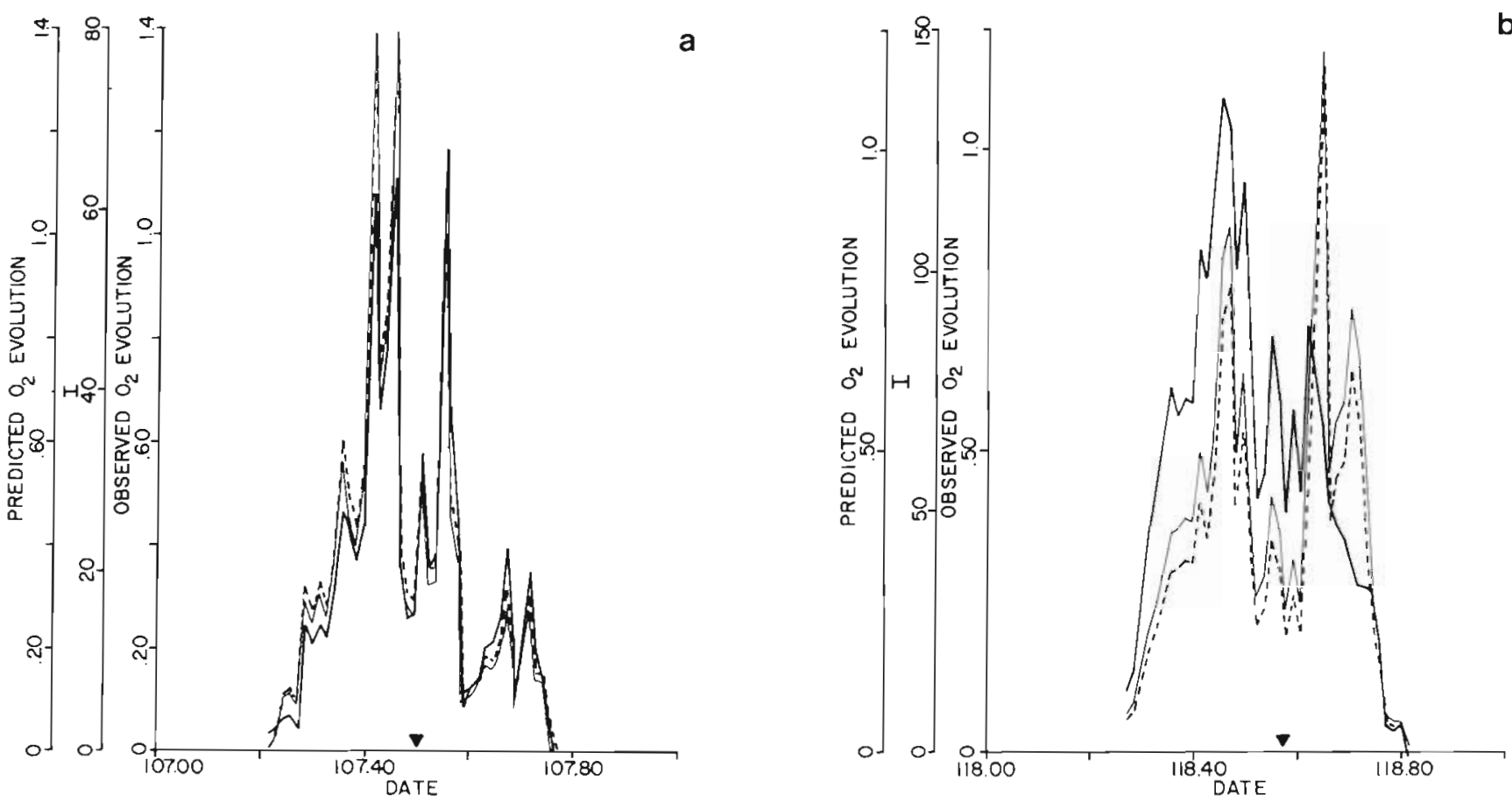

Fig. 2. Thalassiosira fluviatilis. Observed photosynthesis over the course of a day (heavy solid line) and that predicted on the basis of a P-I curve (light solid line) plotted with irradiance ( $I$; dashed line). The sample for the P-I curve was taken at the time of day indicated by the inverted triangle. The day is divided into decimal fractions and the date is a sequential number for day of year; the Julian date in Table 1. (a) Day 107; (b) Day 118 

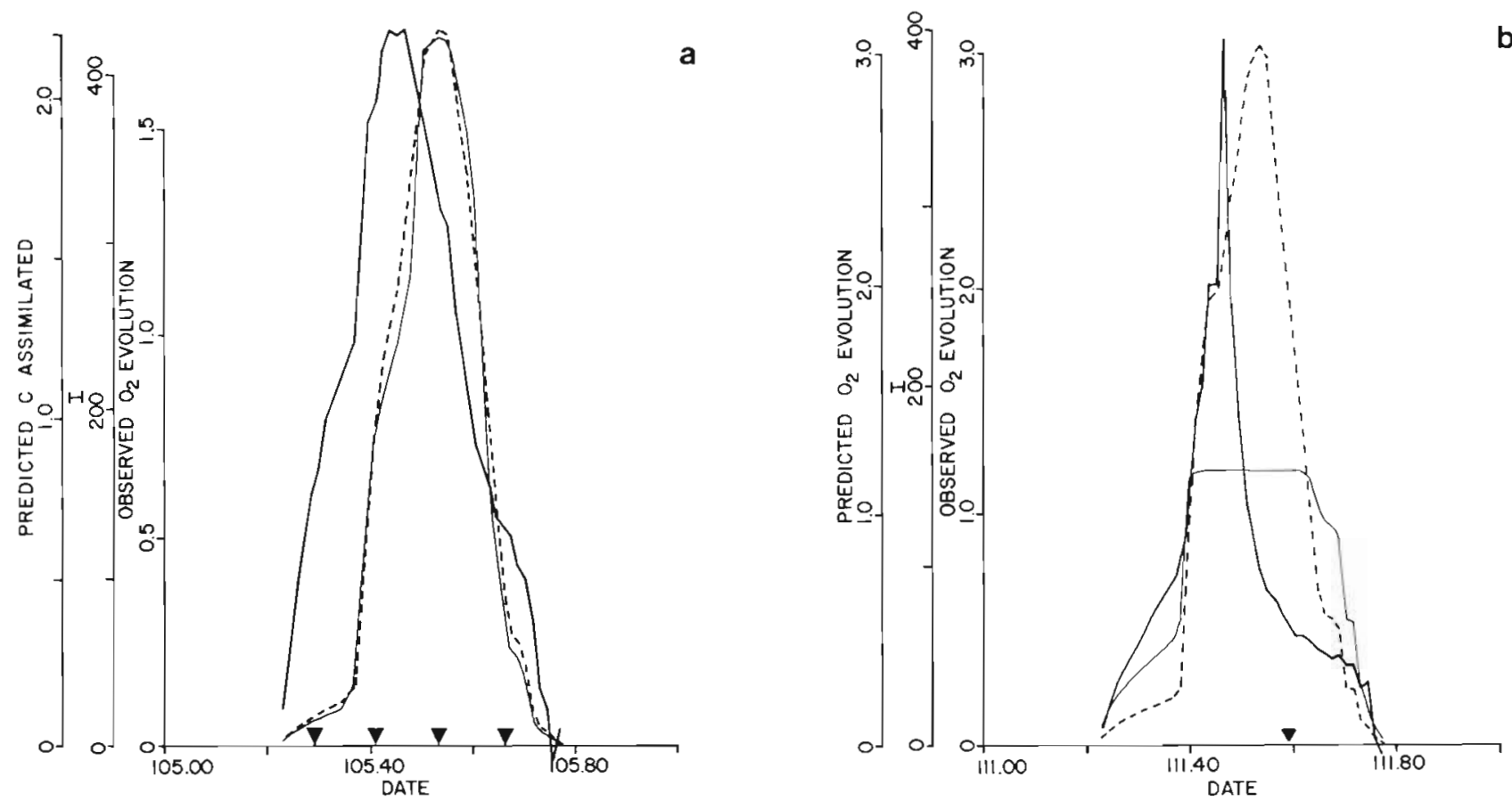

Fig. 3. Same as Fig. 1, for 2 sunny days. Note scale changes. (a) Day 105; (b) Day 111

The same is true for days categorized as having variable irradiance (Fig. 4). P-I curves are unable to predict the short-term behavior in photosynthesis even when 4 P-I measurements are made during the day (Fig. 4a).

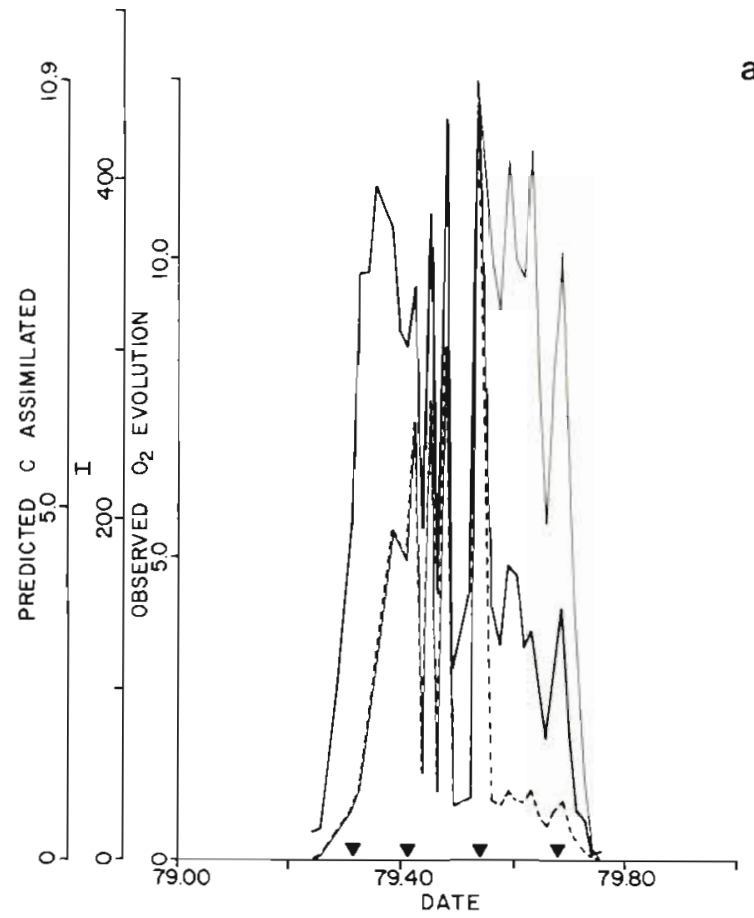

a
While P-I curves do not predict short-term behavior of photosynthesis for solar irradiance greater than some saturating value, they seem to have enough information such that prediction of daily integrals of photosynthesis in the culture fares much better (Table

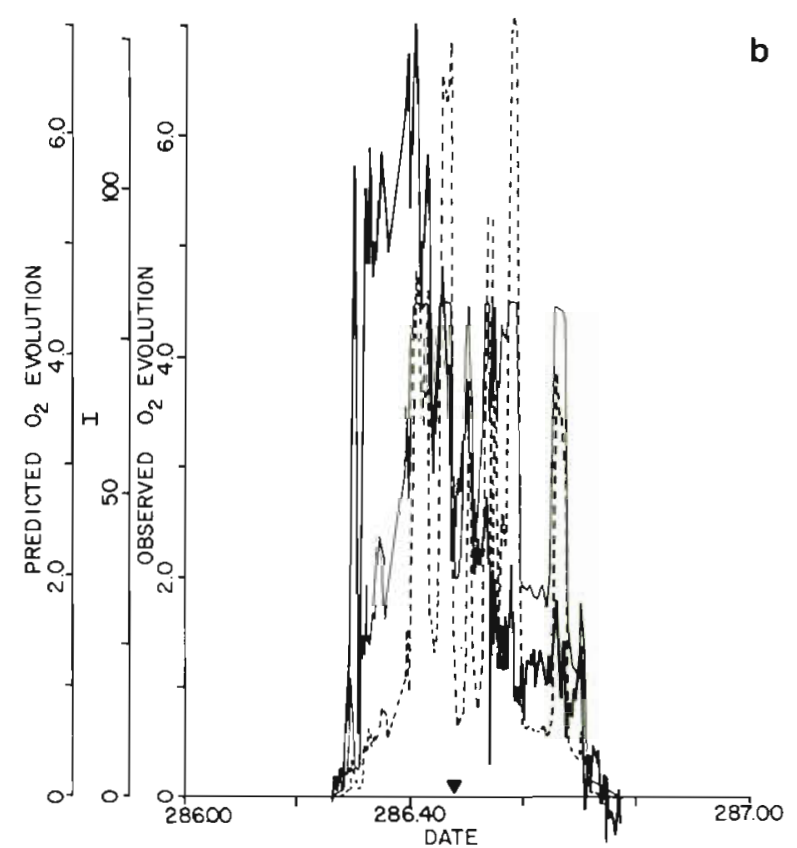

Fig. 4. Same as Fig. 1, for 2 days characterized by short-term irradiance variability. The organism used in (a) was Lauderia borealis. (a) Day 79; (b) Day 286 
1). The difference, here expressed as the quotient of the observed and predicted daily photosynthesis, is within $20 \%$ of the expected value of unity in 9 out of 17 experiments. Much of the reason for this agreement is that the total daily irradiance for many of the days is low enough for predictability to be improved. The worst predictions are on days in which total daily irradiance was high combined with a single $P$ vs I measurement at or after $1200 \mathrm{~h}$ (e.g. days 99, $110 \& 111$ in Table 1). Aside from analytical errors, there are at least 3 reasons for the differences in observed and predicted total daily photosynthesis. First, we have no evidence that the difference (OBS/PRE) is other than normally distributed (K-S test, $\mathrm{P}<0.01)$. This suggests that the errors involved in the predictability of P-I curves are random. Second, the photosynthetic quotient $(P Q)$ will vary both between and within days with changing metabolic requirements of the cells. This should affect the comparisons using the ${ }^{14} \mathrm{C}$ technique, which, given a nominal range of $P Q$ of 0.5 to 1.5 , could produce potential errors of $\pm 50 \%$. Finally, we have retained a 'respiration' term in Equation (3), actually a photosynthetic rate at zero irradiance. The effect of this term is expected to be small. We conclude that while the P-I curves do not predict the instantaneous rates of photosynthesis, or within-day photosynthesis behavior, good predictions of the daily integral of photosynthesis are possible.

Whether ${ }^{14} \mathrm{C}$-uptake measures net or gross photosynthesis (Peterson 1980) cannot be resolved with these data (Fig. 3a \& 4a). The equivalence, in a statistical sense, in prediction based on ${ }^{14} \mathrm{C}$ or oxygen evolution suggests that ${ }^{14} \mathrm{C}$-uptake measures net photosynthesis. This agrees with the laboratory study of Smith \& Platt (1984) for Thalassiosira pseudonana. Alternatively, theoretical considerations (e.g. Dring \& Jewson 1982) suggest that for these short incubations, ${ }^{14} \mathrm{C}$-uptake measures gross photosynthesis. If this is so, then algal respiration during the photoperiod should be very small,

\section{DISCUSSION}

For days of low irradiance, the fitted P-I curves predict both instantaneous and integral photosynthesis very well. This can be interpreted as the P-I parameter $\alpha$ having a long time constant (Harris \& Piccinin 1977), and also agrees with the supposition that $\alpha$ may be used more advantageously than $\mathrm{p}_{\max }$ in a modeling sense (Bannister 1974), in spite of the wider confidence limits of its measurement in natural populations (Platt et al. 1977). However, for sunny days and for days with periods of sunshine alternating with clouds, it is not possible to reconstruct the variability of details of the photosynthetic behavior using the information from the fitted P-I curves, as produced using techniques of current practice. The P-I curve is measuring something quite different from short-term photosynthesis, even under these idealized laboratory conditions.

It is possible that the act of taking a sample, and the periods of darkness or low light intensity during sample preparation, followed by constant irradiance during the P-I measurement produces a response different than actual photosynthetic behavior under natural light variability. This kind of bias would occur under any measurement situation, since water samples from natural environments must be perturbed (i.e. captured and placed in a bottle) in order for the measurement to be made. This bias shows up most clearly when the $\mathrm{P}$ vs I measurement was made in the afternoon (Fig. 3b $\& 4 a$ ), and would explain why, in those cases, P-I curves predict a higher rate of photosynthesis than observed at the time the sample was removed from the culture. Apparently, neither the morning maximum nor the afternoon depression are persistent phenomena. In other of our data (Marra \& Heinemann 1982, Marra unpubl.), late-afternoon recovery of photosynthetic rate following a mid-afternoon depression is sometimes observed, such as during a late afternoon sunny period preceded by an overcast condition. Nevertheless, in these short incubations, the $\mathrm{P}$ vs I measurement seems to preserve some physiological aspects of the original population, although we must regard the data in Fig. 1, and in other studies of the diurnal behavior of P-I curves, as representing only an approximation to the kind of behavior possible. In order for the integrals to agree, the P-I curve would have to predict some averaged responses to light instead of the more transient response observed in the culture. A model which predicts the short-term behavior of photosynthesis for similar data using a P-I formulation with time-varying parameters is currently under development (Neale \& Marra 1982, Neale \& Marra 1985).

The physiological reasons for the lack of agreement between P-I curve predictions of instantaneous rates of photosynthesis, on the one hand, and on the other the agreement in the integral, remain problematic. The transient behavior which produces the mismatch between observed and predicted photosynthesis may arise from imbalances in the kinetics of photosynthetic electron transport (Marra \& Heinemann 1982) or carbon assimilation (Bassham et al. 1978, Walker \& Robinson 1978), or from photorespiration (Harris \& Lott 1973) or chlorophyll a turnover (Riper et al. 1979). For the day in which the P-I experiments in Fig. 1 were performed, the coefficient of variation in chlorophyll $a$ is only $16 \%$, and is not consistent with the diurnal variability observed. These imbalances in kinetics may then be 
averaged out over the longer term, or under conditions of low or constant irradiance.

A more practical matter is the use of P-I curves to predict production in natural communities. The use of only 2 genera of diatoms grown under conditions of nutrient sufficiency, at relatively high temperature $\left(20^{\circ} \mathrm{C}\right)$, and at moderate dilution rates $\left(0.5\right.$ to $\left.1.0 \mathrm{~d}^{-1}\right)$, makes extrapolation to natural situations uncertain. There can be species-dependent variation in transient or short-term photosynthetic behavior alone (Marra 1980). Also, within the range of light intensities in our work (both natural and artificial), we have not observed, nor are we able to parameterize, photoinhibition in the steady state sense (Platt \& Gallegos 1980). The decrease in $p_{\max }$ over the period of a day, however, can certainly be regarded as a form of photoinhibition. Finally, we are not able to evaluate how the predictive value of P-I curves changes with depth, although it might be expected that predictive value would increase with depth since $a$ is less subject to variation (Fig. 2).

Given the above reservations, the P-I relationship appears useful in a modeling context. It contains sufficient physiological information to produce good agreement in the daily integrals under certain conditions, and this is encouraging for models of the type first developed by Talling (1957). Even though the fitted P-I curves (as produced here) were not able to reproduce accurately the hourly behavior of photosynthesis for sunny days, an elaboration of the steady-state P-I model with time varying parameters is likely to improve predictability at that time scale (Neale \& Marra 1982, Neale \& Marra 1985).

Acknowledgements. We thank P. G. Falkowski, T Owens and $J$. White for suggestions in designing the cuvette for oxygen evolution measurements used to produce the P-I curves. This research was supported by National Science Foundation Grant OCE 78-19450 and Office of Naval Research Contract N00014-84-C0132-IIA. Lamont-Doherty Geological Observatory Contribution 3815.

\section{LITERATURE CITED}

Bannister, T. T. (1914). Production equations in terms of chlorophyll concentration, quantum yield, and upper limit to production. Limnol Oceanogr. 21: 326-336

Bassham, J. A., Krohne, S., Lendzian, K. (1978). In vivo control mechanism of the carboxylation reaction. In: Siegelman, H. W., Hind, G. (ed.) Photosynthetic carbon assimilation. Plenum Press, New York, p. 77-93

Dring, M. J., Jewson, D. H. (1982). What does ${ }^{14} \mathrm{C}$ uptake by phytoplankton really measure? A theoretical modelling approach. Proc. R. Soc. 214: 351-368

Fee, E. J. (1969). A numerical model for the estimation of photosynthetic production, integrated over time and depth, in natural waters. Limnol. Oceanogr. 14: 906-911
Fee, E. J. (1973). Modeling primary production in water bodies: a numerical approach that allows vertical inhomogeneities. J. Fish. Res. Bd Can. 30: 1469-1473

Gallegos, C. L., Platt, T. (1981). Photosynthesis measurements on natural populations of phytoplankton: numerical analysis. Can. Bull. Fish. aquat. Sci. 210: 103-112

Harding, L. W., Jr., Meeson B. W., Tyler, M. A. (1983). Photoadaptation and diel periodicity of photosyntheses in the dinoflagellate Prorocentrum mariae-lebouriae Mar. Ecol. Prog. Ser 13: 73--85

Harris, G. P. (1973). Diel and annual cycles of net plankton photosynthesis in Lake Ontario. J. Fish. Res. Bd Can. 30: 1779-1787

Harris, G. P., Lott, J. M. A. (1973). Light intensity and photosynthetic rates in phytoplankton. J. Fish. Res. Bd Can. 30: 1771-1778

Harris, G. P. Piccinin, B. B. (1977). Photosynthesis by natural phytoplankton populations. Arch. Hydrobiol. 80: 405-457

Jassby, A. D., Platt, T. (1976). Mathematical formulation of the relationship between photosynthesis and light for phytoplankton. Limnol. Oceanogr. 21: 540-547

Malone, T. C., Neale, P. J. (1981). Parameters of light-dependent photosynthesis for phytoplankton size fraction in temperate estuarine and coastal environments. Mar. Biol. 61: $289-297$

Marra, J. (1978). Phytoplankton photosynthetic response to vertical movement in a mixed layer. Mar. Biol. 46: 203-208

Marra, J. (1978). Vertical mixing and primary production. In: Falkowski, P. G. (ed.) Primary productivity in the sea. Plenum Press, New York, p. 121-137

Marra, J. and Heinemann, K. (1982). Photosynthesis response by phytoplankton to sunlight variability, Limnol. Oceanogr. 27 : 1141-1153

Neale, P. J., Marra, J. (1982). The time dependence of photosynthetic parameters in cultures exposed to natural light. EOS Trans. Am. geophys. Un. 63: 95

Neale, P. J., Marra, J. (1985). Short term variation of Pmax under natural irradiance conditions: A model and its implications. Mar. Ecol. Prog. Ser. (in press)

Peterson, B. J. (1980). Aquatic primary productivity in the ${ }^{14} \mathrm{C}$ $\mathrm{CO}_{2}$ method: A history of the productivity problem. Ann. Rev. Ecol. Syst. 11: 359-385

Platt, T., Jassby, A. D. (1976). The relationship between photosynthesis and light for natural assemblages of coastal marine phytoplankton. J. Phycol. 12: 421-430

Platt, T., Jassby, A. D., Denman, K. L. (1977). Modelling the productivity of phytoplankton. In: Goldberg, E. D. (ed.) The sea, Vol. VI. John Wiley, New York, p. 807-856

Platt, T., Gallegos, C. L. (1980). Modelling primary production. In: Falkowski, P. G. (ed.) Primary productivity in the sea. Plenum Press, New York, p. 339-362

Prezelin, B. B., Matlick, H. A. (1980). Time-course of photoadaptation in the photosynthesis-irradiance relationship of a dinoflagellate exhibiting photosynthetic periodicity. Mar. Biol. 58: 85:96

Riper, D. M., Owens, T. G., Falkowski, P. G. (1979). Chlorophyll turnover in Skeletonema costatum, a marine plankton diatom. Pl. Physiol., Lancaster 64: 49-54

Smith, R. E. H., Platt, T. (1984). Carbon exchange and ${ }^{14} \mathrm{C}$ tracer methods in a nitrogen-limited diatom, Thalassiosira pseudonana. Mar. Ecol. Prog. Ser. 16: 75-87

Steele, J. H. (1962). Environmental control of photosynthesis in the sea. Limnol. Oceanogr. $7: 137-150$

Talling, J. F. (1957). The phytoplankton population as a compound photosynthetic system. New Phytol. 56: 133-149

Vollenweider, R. A. (1965). Calculation models of photosyn- 
thesis-depth curves and some implications regarding day rate estimates in primary production measurements. Memorie Ist. ital Idriobiol. 18 (suppl.): 425-457

Vollenweider, R. A. (1970). Models for calculating integral photosynthesis and some implications regarding structural properties of the community metabolism of aquatic systems. In: Setlik, I. (ed.) Prediction and measurement of photosynthetic productivity. Pudoc, Wageningen, $p$. $455-472$
Walker, D. A., Robinson, S. P. (1978). Regulation of photosynthetic carbon assimilation. In: Siegelman, H. W., Hind, G. (ed.) Photosynthetic carbon assimilation. Plenum Press, New York, p. 43-60

Yentsch, C. S. (1980). Light attenuation and phytoplankton photosynthesis. In: Morris, I. (ed.). The physiological ecology of phytoplankton. Univ, of California Press, Berkeley, p. $95-127$

This paper was submitted to the editor; it was accepted for printing on March 31, 1985 